\title{
Designing Authentic Cybersecurity Learning Experiences: Lessons from the Cybermatics Playable Case Study
}

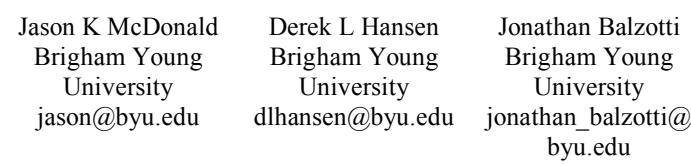

\author{
Tanner Johnson \\ Brigham Young \\ University \\ tannerwj@ \\ gmail.com
}

\author{
Desiree Winters \\ Brigham Young \\ University \\ winters.desiree \\ @gmail.com
}

\author{
Justin Giboney \\ Brigham Young \\ University \\ justin giboney \\ (a)byu.edu
}

\author{
Elizabeth \\ Bonsignore \\ University of \\ Maryland \\ ebonsign@umd.edu
}

\begin{abstract}
This paper reports our work on an educational simulation that we call the Playable Case Study (PCS). A PCS is characterized by a fictitious narrative integrated with real-world learning activities, helping students learn skills, knowledge, and dispositions relevant to a professional career. We describe a recent pilot test of a PCS focused on the discipline of cybersecurity, emphasizing the kinds of tensions and difficulties that can arise during the development of immersive, experiential learning experiences: a) challenges accompanying the work of interdisciplinary PCS teams, particularly maintaining technical accuracy while still developing an authentic and engaging narrative; $b$ ) reconciling the opportunities provided by the philosophy of the simulation with the need to scaffold educational experiences to support students' capabilities; and c) integrating the PCS into the classroom environment. We also provide design recommendations, in the form of questions that others can consider if they are attempting to create similar educational experiences.
\end{abstract}

\section{Introduction}

One of the persistent challenges in education is how to help students learn more than the knowledge and practical skills of a discipline, but also the metacognitive and soft skills that are necessary for professionals to be successful over the course of a career [1]. While technological solutions have provided promising results, they can be costly to develop, not only initially but as additional costs of maintenance and other updates accrue over time [2]. This can be particularly true for cutting-edge, immersive technologies that not only offer intriguing results but are also highly engaging and have proven abilities to capture peoples' attention in sectors other than education.
One such technology is that of the educational simulation: an immersive pedagogy that places students in a role where they learn knowledge and skills within an authentic context [3]. Related to simulations are certain forms of gaming that can also have educational benefits. An example of a game that shares many characteristics with simulated environments is the alternate reality game (ARG), an emerging class of interactive fiction, "where players collaboratively hunt for clues, make sense of disparate information, and solve puzzles to advance an ever-changing narrative that is woven into the fabric of the real world" [4, p. 25]. ARGs are unique in their demand for the "This is Not a Game" (TINAG) ethos, wherein all activities related to the game are presented as part of the gameworld, making it easy for players to engage in authentic ways. While most ARGs have focused on entertainment [5] and marketing [6] domains, educators have also began experimenting with the form [7-8]. However, as onetime events, ARGs are costly to develop and difficult to integrate into traditional educational environments, highlighting a need to blend immersive ARG techniques with more replayable educational simulations designed for formal learning settings $[4,8]$.

In this paper we present some of our work on a form of educational simulation that draws on affordances of the broader educational simulation genre [3], case study instruction [9], and educational ARGs [7-8]. We call this new genre of educational simulation a Playable Case Study (PCS). What makes PCSs particularly promising is their blending of strategies from ARGs that increase immersion and authenticity, alongside case study and educational simulation approaches designed to work in a classroom environment. This makes them highly scalable, as well as authentic and contextually nuanced. While our initial implementations of the PCS approach show promise [10], our experiences designing and running them in multiple classrooms has taught us a great deal about the challenges and opportunities afforded by this new genre. Our purpose in this paper is to describe key design tensions and difficulties that arise 
during PCS development, and provide design recommendations to others designing similar educational experiences.

Our paper is organized as follows. First, we briefly describe the characteristics of the PCS genre. Second, we situate the PCS in scholarly literature on both the design of educational materials, and theories of instructional theory and learning. Third, we report some of the design and implementation issues observed during a recent pilot study of a PCS called Cybermatics, that focuses on teaching cybersecurity concepts and skills. And fourth, we discuss strategies our team has learned about how to design and develop a PCS, based on our experience designing Cybermatics.

\section{Background}

\subsection{The PCS as a Type of Educational Simulation}

While the PCS has similarities to other forms of instructional simulations and epistemic games [11], it also has some qualitative differences that justify its identification as a distinct form of the genre. This is due in part to blending techniques of educational/classroom simulations with immersive techniques from the ARG, particularly the transmedia interface, mystery narrative, the assuming of in-experience roles/identities by players, meaningful forms of participation that can affect the outcome of the story, and the TINAG ethos that embeds the tools, messages, and interactions of the game into players' everyday lives [6]. Detailed descriptions of the PCS characteristics can be found in [10]. In this section we briefly summarize some of those characteristics as context for the discussion that follows.

A significant distinction of the PCS from other forms of instructional simulation is that it blends a formal focus on teaching with informal, "real-world" puzzle-solving and mystery narratives. Related to the first point, each PCS is built specifically to align with the learning goals of an educational system, rather than being tied to a prominent event in the world (such as might be seen in a traditional ARG). They are also scoped to be used in an individual class or school, keeping the community small, instead of a large-scale, public community. And they can be expanded by the addition of teacher-generated challenges or lesson elements that are useful in meeting class or school specific needs. Related to this second point, the PCS does adopt forms of interaction common to traditional ARGs, such as the philosophy of This is Not a Game (TINAG) [12]. TINAG means the simulation strives against interface forms that participants perceive to have been manufactured or fabricated. Instead of relying on artificial mechanisms of advancing the game's story like cards, dice, or controlling an avatar on a screen, a PCS uses everyday communication channels such as email, phone calls, text messages, and face-to-face interactions to tell the story, drive player action, and teach material core to the simulation's learning objectives.

The mechanism by which the formal and informal affordances of a PCS are blended typically takes the form of placing students into a realistic role as disciplinary professionals. Students experience this role in an authentic, unfolding narrative that is told using everyday technologies, poses real-world problems, and provides opportunities for reflection. These affordances help students better understand and make connections between the skills, knowledge, identity, dispositions, values, and epistemology unique to that profession [10, 12]. Like "virtual internships" [14], the PCS allows students to take on the role of a professional before they have the expertise to do so in a real-world setting. The specific skills, knowledge, and dispositions the PCS helps students develop are identified as part of the simulation development process, and are correlated with school/program standards to ensure that the game is fully justifiable from an educational perspective. The scenario also includes built-in assessments to test student achievement of the identified learning objectives. Finally, the PCS is also supported by teachers during class time. While the fictional story is meant to bleed into players' real lives as they interact with characters via video-conferencing, email, texting, chatbots, file sharing, and 3D virtual environments, the PCS also integrates classroom lessons into the learning. For example, teachers may provide educational scaffolding that will help them be able to accomplish PCS tasks presented by fictional characters. The typical ARG role of a "puppet master" [6, p. 20], or person who controls the scenario and advances and modifies story elements as needed, is assumed by teachers who receive help themselves in the form of job aids or lesson plans created by the PCS developers.

Initial studies indicate that these PCS affordances can be beneficial to students and teachers in classroom settings. Hansen, Balzotti, Fine et al. [10], tested a PCS by the name of Microcore, teaching the skills of argumentative writing. They reported that the authenticity of the scenario had a direct benefit on students' work, "there is no question that the shared rhetorical context provided in the simulation allowed the instructor to clearly articulate proper approaches to writing for [a] specific audience. . . . the common ground that students and the instructor shared from the simulation supported discussions and feedback about audience at a high level of specificity" (p. 109). Additionally, they reported that students had a positive affective response to the game's authentic scenario that 
also held educational value, "the Microcore simulation helped generate emotional responses, which can lead to important in-class discussions and reflections" (p. 108).

\subsection{Theoretical Support for the PCS}

For professional fields, educational simulations and other experiential learning opportunities have been called an educational form of "reflective practice," meaning they help students (as potential professionals) draw a connection "between knowing and doing" [11]. The design processes used to create such experiences have been identified by Shaffer [15] as a theory of "pedagogical praxis," specifying that "under the right conditions, computers and other information technologies can make it easier for students to become active participants in meaningful . . . practices of life" (p. 1401). When designing for a pedagogy of praxis, teams of technology and content experts engage in processes to a) pilot learning experiences where students learn through acting in manners similar to professionals in a field; b) study how professionals in the field under question are trained; c) develop technologies that integrate findings from the initial pilot and the examination of professional training; d) integrate the technologies into a learning environment that simulates professional learning practices; and e) evaluate and adapt the learning environment, based on measures of student performance as well as observations of how well the experience approximates professional practice.

The value of framing learning situations so as to approximate professional practice can be interpreted in light of theories of "becoming" [16, p. 34]. One of the most well-known of these is Lave and Wenger's theory of situated learning [17]. Lave and Wenger propose that learning occurs when students are initiated into the skills, habits, dispositions, and identity necessary to be successful in a domain through a process they call "legitimate peripheral participation" (p. 29). In summary, this is a process of slowly being integrated into a community by participating on the peripheriesobserving, trying out basic activities under the direction of others or on one's own, reflecting on one's actions, getting advice from more experienced members of the community, and then responding to encouragement to try ever-more central activities that define the boundaries of the field. Yet all of these forms of engagement should also be legitimate, that is, connected to authentic forms of participation and not through exposure in detached or artificial ways. As opposed to being a student in a didactic, presentation style of instruction, being a learner is defined by participating in forms of apprenticeship. Students "'steal' the knowledge they need" [18, p. 49] from the people and environment around them, as it becomes useful for them to solve problems or address other issues they encounter.

Although learning environments that simulate practice have some differences when compared to Lave and Wenger's original theory (for example, they often rely on characters that represent professionals rather than direct access to authentic professionals, themselves), the views on learning provided by the theory help clarify why it is valuable to frame learning in as authentic terms as possible. Doing so can be viewed as an introductory structure that situate knowledge and skills in their legitimate contexts for students to experience, as opposed to decontextualizing them in purely academic environments. The relevant community of practice is introduced to students, possibly in preparation for them to be stronger initial participants in the actual community should they choose to do so.

This sense of introducing students to an authentic community of practice can be seen in the affordances of the PCS. The case study is always centered around some sphere of practice, some set of activities which are representative of those in which disciplinary professionals regularly engage. Even if students are not committed to such a career path, an assumption underlying PCS development is that even a basic introduction to a field should lead students to legitimately experience what it means to work with the subject day-to-day, not just be exposed to a set of topics or skills that professionals may use. But, recognizing that students are novices, the challenges and activities in which they participate are peripheral. This means they are simple enough (on the edge of practice enough) that students can succeed. The game characters, classroom teachers, and other educational scaffolding are provided to help students engage with these peripheral forms of disciplinary participation, encourage them to fully accept their in-game roles, and by so doing legitimately adopt the role of a novice in the field under study.

Learning in such authentic and epistemic environments can also be viewed as an interaction between students and a simplified representation, or model, or a real-world system or environment. This is called the theory of model-centered instruction (MCI), and was proposed by Gibbons [19] to explain how model learning environments can be developed to support students as they navigate the complexity and unpredictability of the learning situation. As students interact with instructional models they can investigate, experiment, or practice skills needed for real-world action, without the risk that can accompany engagement with an actual system or environment. A common example of MCI is a flight simulator which allows pilots to experience new and unusual flight conductions in a 
safe setting. Domains like cybersecurity also pose risks that preclude novices from working on actual systems.

MCI has seven key principles [19]:

- Experience with models - Learning happens as people observe and interact with models of systems, environments, or expert performance. Learning should be supplemented by companions that help students interpret a model (e.g., teachers, or guides like digital assistants).

- Problem solving - Problems are the primary means through which learners interact with the model. Problems are carefully selected by teachers for students to either solve or to observe being solved with the model.

- Denaturing - A model's fidelity to the real world is decreased to make it simpler or safer, to highlight processes otherwise difficult to observe, or to make uncommon phenomena occur more frequently.

- Sequence - Problems are ordered by task, size, or other characteristics.

- Goal orientation - Problems are chosen to support the particular instructional goals of a situation.

- Resourcing - Additional resources can be provided to help students interact with the model.

- Instructional augmentation - Models can be can supplemented with additional instructional materials, to assist students and teachers during the problem-solving process.

Table 1. Comparing $\mathrm{MCl}$ to the PCS

\begin{tabular}{|l|l|}
\hline $\begin{array}{l}\text { MCI } \\
\text { principle }\end{array}$ & Corresponding PCS feature \\
\hline $\begin{array}{l}\text { Experience } \\
\text { with models }\end{array}$ & $\begin{array}{l}\text { Game narratives are models of real- } \\
\text { world work situations; the teacher } \\
\text { serves as a learning companion } \\
\text { throughout the experience and at } \\
\text { least one character plays the role of } \\
\text { a protagonist by proxy [20], helping } \\
\text { model behavior. }\end{array}$ \\
\hline $\begin{array}{l}\text { Problem } \\
\text { solving }\end{array}$ & $\begin{array}{l}\text { Players must complete a series of } \\
\text { problem-based challenges each } \\
\text { virtual day to advance the narrative. }\end{array}$ \\
\hline Denaturing & $\begin{array}{l}\text { Players have clearly defined tasks } \\
\text { for each virtual day, use a } \\
\text { sandboxed intranet for collaborating } \\
\text { with fictional characters that only } \\
\text { includes needed features and tools, } \\
\text { and allow students to deal with high } \\
\text { risk situations they could not } \\
\text { otherwise deal with. }\end{array}$ \\
\hline Sequence & $\begin{array}{l}\text { The game narrative is carefully } \\
\text { sequenced into virtual "days" that } \\
\text { include tasks for students to }\end{array}$ \\
\hline
\end{tabular}

\begin{tabular}{|l|l|}
\hline & $\begin{array}{l}\text { accomplish. Completing tasks } \\
\text { provides the information to advance } \\
\text { the narrative. }\end{array}$ \\
\hline $\begin{array}{l}\text { Goal } \\
\text { orientation }\end{array}$ & $\begin{array}{l}\text { A PCS narrative, challenges, and } \\
\text { communication platform are } \\
\text { developed from the beginning to } \\
\text { support specified learning goals of } \\
\text { three main types: dispositions, } \\
\text { skills, and knowledge }\end{array}$ \\
\hline Resourcing & $\begin{array}{l}\text { "In-game" resources, such as } \\
\text { internal documentation, computer- } \\
\text { generated chat messages, video } \\
\text { clips (made to look like live video- } \\
\text { conferences), and email messages } \\
\text { from fictional characters provide all } \\
\text { resources needed to successfully } \\
\text { play through the PCS. Teachers and } \\
\text { assistants can supplement pre- } \\
\text { crafted content by sending } \\
\text { messages as fictional characters. }\end{array}$ \\
\hline $\begin{array}{l}\text { Instructional } \\
\text { augmentation }\end{array}$ & $\begin{array}{l}\text { Classroom teachers are given } \\
\text { lesson supplements or other } \\
\text { curricular materials to support } \\
\text { students throughout the game. As is } \\
\text { standard for traditional case study } \\
\text { teaching, materials for PCSs include } \\
\text { discussions and in-class } \\
\text { assignments that help students } \\
\text { reflect meta-cognitively on the } \\
\text { narrative, learning outcomes, and } \\
\text { their own attitudes toward the PCS. }\end{array}$ \\
\hline
\end{tabular}

Table 1 shows how the principles of MCI map with the characteristics of the PCS.

\section{Method}

This paper is part of a broader study into the affordances and outcomes of Playable Case Studies in cybersecurity education. Our purpose here is to analyze the tensions and difficulties that can arise when developing a PCS, and to provide design recommendations to others designing similar educational experiences. Other evaluations of Cybermatics report the promising outcomes of pilot tests using the PCS [21].

To analyze the development of this PCS we employed an action research methodology, where we as educator-researchers engaged in an authentic design project "to solve a practical problem," while using the project to "make meaning of . . . a particular phenomenon" [22, p. 49]. The practical problem was to develop a PCS that could be used to teach cybersecurity concepts to undergraduate students in an introductory IT course taught by one of the authors of this paper. PCS 
development proceeded under a process similar to Shaffer's [15] pedagogical praxis; our study represents part of phase five of Shaffer's approach, “outcome and process measures" (p. 1406). This means the phenomena we studied were the tensions and difficulties arising in PCS development, using the project as a case study. We describe our research methodological choices using action research principles as described by Merriam and Tisdell—plan, act, observe, reflect [22].

Planning consisted of designing and developing a PCS to address an observed problem in cybersecurity education: by 2022 an estimated 1.8 million cybersecurity positions will be unfulfilled, in addition to the technical jobs in many other fields that will require some level of cybersecurity knowledge [20-21]. A detailed description of the resulting PCS, called Cybermatics, can be found in Giboney et al. [21] and so is only summarized here. The learning goals of the PCS are for students to (1) develop skills and understand dispositions needed for cybersecurity careers; (2) increase their self-efficacy that they can be successful in a cybersecurity career; and (3) inform a decision as to whether a career in cybersecurity is right for them. Cybermatics consists of five simulated days in the professional life of a penetration tester (i.e., "red team" member). Students begin employment at a cybersecurity firm known as Cybermatics on the first day of a penetration test for a home automation company called Riptech. The goal of the penetration test is to ethically hack into the Riptech system in order to identify existing vulnerabilities so they can be patched. Technical tasks included performing SQL injection, cracking passwords, finding hidden files in a Linux system, and report writing.

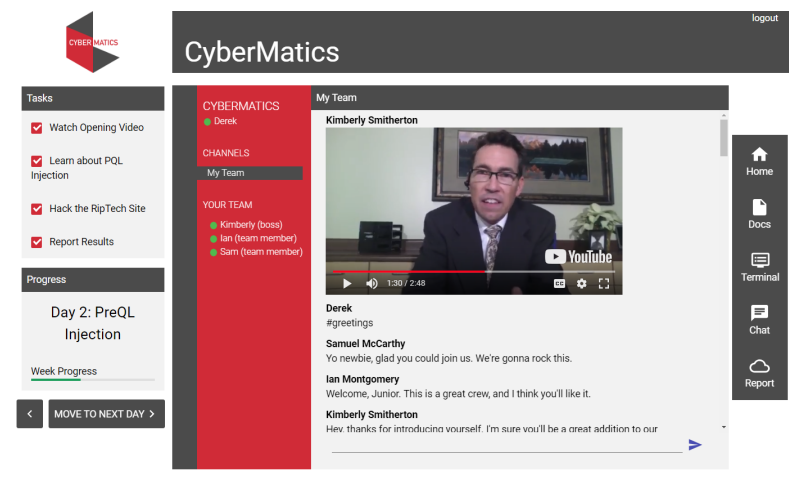

Figure 1. The basic Cybermatics interface

By completing each day in the PCS, students learn the terminology, the skills to complete basic tasks, and the soft skills of working in a penetration test environment, in a manner that a professional might need to be successful in a real-world situation. Tasks for each day are assigned by the team lead character and completed through a simulated set of tools, including a Terminal shell for running Linux commands, a Slacklike chat messaging system (actually a simple chatbot) that includes video conferencing (pre-recorded video segments), a documentation section for code documentation and training guides, and a reporting section for co-authoring the final penetration testing report. As they complete the PCS, students discover a Riptech employee has built in a backdoor to the Riptech system, allowing hackers to access customer data such as video feeds. Their investigation results in identifying the employee and recording evidence of the wrongdoing, both of which are presented to the Riptech $\mathrm{CEO}$ and summarized in a final report.

The Act phase of our research consisted of a pilot test of the Cybermatics PCS in the fall of 2017. 61 students completed the simulation in an introductory IT course at a university in the western United States. Participants ranged from college freshman to seniors, though the majority were freshman or sophomores $(63 \%) .84 \%$ of the students were men and $16 \%$ women-consistent with the demographic breakdown of the major. This course is required for IT majors and minors, but is also taken by students of other majors to decide if they want to become an IT student or if they are interested in a basic introduction to the field. Also of note is that around $35 \%$ of IT students at this university focus on cybersecurity as an emphasis, although they often do not decide this until later in their program. Students completed the PCS near the end of the semester, after they had been introduced to concepts used in the simulation such as databases, cybersecurity (at a very high-level), Linux, and web technologies.

Observing occurred throughout the pilot, with data gathered using a mixed-method approach. First, members of the design team observed students completing the PCS in a computer lab. Their experiences were captured either through personal notes or by the lead author, who collected their perceptions through one-on-one interviews or through "postmortem" style team meetings, and provided information about how the team perceived their design decisions were received by students. Second, the interviews and meetings also included discussion of difficulties that arose throughout the PCS design and development process. Perceptions of team difficulties were triangulated with information recorded about the student observations to generate insights as to possible impacts of design and development team interactions. Third, students completed pre- and post-surveys to collect information about their experience with the PCS. 51 of the 61 students in the class completed both surveys, with 54 completing the post-survey, specifically. While most of the survey questions related to the simulation's 
learning outcomes and so are not reported in detail here, three questions from the post-survey provided qualitative comments from students about how they perceived the effects of design decisions made by the team: a) What did you like about the simulation? b) What could be improved in the simulation? and c) How have your perceptions about cybersecurity changed after completing the simulation? Responses were coded by two of the authors using an iterative process wherein the key themes emerged from the data. After a code-book was established and updated, the two coders independently coded all responses and had a Cohen's Kappa agreement above 0.9 for all categories. Responses to these questions were triangulated with other data sources to confirm insights, clarify interpretations of the data, or offer alternative views. Fourth, artifacts created throughout PCS development (such as planning documents or components of the final PCS) were compared to other data sources to provide additional clarification and triangulation of findings.

Finally, the Reflection phase of our research was primarily conducted by the lead author, and make up the rest of this paper. This consisted of identifying themes in the data collected throughout the study (e.g., interviews, coded survey data); comparing/contrasting themes to find commonalities and/or points od divergence; combining themes where possible to create a reporting structure that synthesizes the tensions and difficulties experienced by the design team, how those impacted the PCS pilot test, and lessons learned about PCS development that are of interest to other practitioners and researchers. Drafts of these reflections were shared with other authors of the study and members of the design team for their input. Based on their suggestions, the results were revised, clarified, and condensed into their final form.

\section{Results}

Our data indicate that creating mixed reality learning experiences like the PCS require the design and development team supporting the educational environment to cope with limiting factors in the broader environments in which they work (both the educational system and within their design teams). These factors can impact the ability of teams to implement with fidelity all the affordances of the PCS strategy, and so require careful and creative planning to respond to limitations while also achieving outcomes the PCS is meant to achieve. We report three key factors that had an impact on the Cybermatics PCS pilot. First, challenges accompanying the work of interdisciplinary PCS teams, particularly maintaining technical accuracy while still developing an authentic and engaging narrative. Second, reconciling the opportunities provided by the
TINAG philosophy with the need to scaffold educational experiences to support students' capabilities. Third, integrating the PCS into the classroom environment.

\subsection{Interdisciplinary Teamwork}

Designing and developing a PCS requires expertise from multiple fields to create a compelling and authentic educational environment, yet the practicalities of bringing together an interdisciplinary team creates challenges that the team must be prepared to address from the beginning. The clearest example in developing the Cybermatics PCS was the relationship between the subject matter experts and the creative writers. Writers most often do not have the expertise necessary to accurately portray the technical details of a field like cybersecurity. This is rarely a problem in many situations in which they find themselves, such as writing a novel or writing for television. But in education it matters whether the details are correct. This challenge is not unique to PCS development, such as can be seen in concerns about the impact of fantastical science fiction on the learning of accurate, real-world science [25]. Conversely, relying upon the technical experts to write narrative elements for a PCS, or to specify the underlying structure and outline of the story, can result in an inauthentic narrative that does not engage students. Given the tight integration the PCS makes between educational outcomes and its narrative challenges or other elements, finding the proper relationship between a team's technical and creative experts is imperative.

Throughout the work of our design team, we noticed that the order in which we perform various activities has a large effect on how much material generated by the writers is usable and how much ultimately needs to be replaced. First, we collaboratively identified the core learning objectives through interviews with professionals (e.g., penetration testing team members in the case of Cybermatics). These interviews were conducted by writers, content experts, and educators. We found that each participant asked different questions, all of which were important to design an effective PCS. Content experts asked about nuances in the types of activities and tasks that penetration testers performed, which often required significant technical knowledge. Writers asked about the context in which the work occurs and encouraged experts to tell stories about their own experiences. And educators asked questions about the types of knowledge, skills, and dispositions students needed to be successful. Because teammembers heard each other's questions, these interviews helped to create a common ground for later discussions.

Once the team had decided upon the learning outcomes and established common ground through the 
interviews, the writing and technical members collaborated closely on developing an overall narrative theme and architecture that was compatible with the PCS's educational purpose. It was essential that the entire team participate in this exercise. For example, based on their knowledge, content experts helped contribute specific ideas about the types of attacks that were prevalent in professional practice (e.g., SQL injection; password cracking), and the types of companies that were attractive targets (e.g., Internet of Things companies). Meanwhile, writers helped generate compelling story arcs and plotlines that included elements of discovery and surprise (e.g., a rogue employee ultimately being the source of the hacks). Educators reminded the team to keep all elements simple, and had useful ideas on how to structure the activities in a meaningful way so students wouldn't get lost in the details. The end result was a framework that included the learning outcomes, activities, and plot advancements that would occur on each of the 5 days.

After this framework was developed, work by the different teams could be completed independently: content experts designed specific activities with input from the educators; writers created character profiles, website content, chat messages, and video scripts; and educators developed educational scaffolding (both ingame and out-of-game) and performed testing of the activities to identify problem points that students might experience. Finally, content experts performed a careful review of all written content to make sure specific references to technologies were accurately worded. Likewise, educators and writers peer reviewed content written by content experts (e.g., documentation used as educational scaffolding) to help clarify it and make it better adhere to the TINAG (e.g., "in-game") ethos, when needed. We found that a bi-weekly meeting was sufficient to coordinate all these activities.

As we reviewed student comments from the Cybermatics pilot we were persuaded that our attempts to reconcile the work of our interdisciplinary team was successful. In their open-ended responses to the question about what they liked about the PCS, 56\% of students reported that they valued the authentic character of the narrative, as reflected in the following comment, "I loved everything about the simulation. It felt very real and the storyline was interesting." And $26 \%$ of students specifically recognized the educational benefits they derived from technical accuracy, as summarized by the student who said the PCS, "gave me an idea of the type of tasks cybersecurity people do to keep information safe."

\subsection{Reconciling TINAG and Educational Scaffolding}

Another tension experienced by the design team was between adhering to the spirit of TINAG and narrative realism, while also providing enough educational scaffolding to support novice students. As noted, realism was an important attribute of the PCS that students recognized (being specifically mentioned by $56 \%$ of students). Some comments seem specifically to point towards the value of TINAG, such as a student who noted, "I enjoyed how it allowed you to actually hack and figure things out and how realistic the people felt." Other students described specific components of the PCS that they perceived to be especially realistic, such as one who said, "I really liked how you got to feel like you were really getting into a website and sever. I thought it was cool to be able to perform a real SQL injection." The terminal was especially recognized by students as a helpful component, with $89 \%$ of students stating it helped the PCS feel more realistic. One student summarized the value of the terminal by saying, "I didn't expect it to feel realistic, and it really did. Everything felt well-polished and real, but what really brought the whole simulation together was the Linux terminal. Being able to navigate a workspace like that in a simulated terminal blew me away."

Providing a completely realistic environment, however, made it difficult to fully support some students in achieving the learning goals of the PCS. $69 \%$ of students described needing clearer instructions, better directions, more help at key moments in the PCS, etc. While all of these are reasonable expectations of a classroom learning experience, each of them can impact TINAG because what is notable about professional environments is often how ambiguous instructions, directions, and other guidelines actually are. Yet as we reflected on comments from the post-survey we recognized that not providing students more background could lead them to become frustrated, overwhelmed, and feel like they did not have the skills needed to complete the tasks. One student said that it would be helpful to have, "better explanation in the documents on how to do what we are supposed to do. For someone who hasn't had very much background it was a little difficult to do in some areas." This type of comment became more pointed from students with little background in technology, such as one who confessed, "I would not have been able to complete the simulation without the help of the TAs or friends around me. [This class] has been my only experience with coding, security, and computers. . . . I studied the scope document and Googled it but still had trouble figuring out what I needed to do. I got stuck a few times, probably because I am not very good with technology and not completely familiar with IT terms and what the task was asking." 
Contrasting these student responses uncovers a difficult design challenge concerning PCS development, or any educational situation in which authenticity to the real world is a crucial characteristic. TINAG is partially meant to draw students into the simulation and keep interest and engagement high, especially for those bringing some background knowledge to the simulation. But given our goal of increasing student self-efficacy about the topic we cannot ignore students like the one who reported not being, "very good with technology." If a PCS is meant to increase self-efficacy, but instead reinforces students' prior mindsets about technology, cybersecurity, or their own abilities to be successful, then the balance between TINAG and denaturing has not been properly achieved. As suggested by the MCI principle of denaturing, designers of educational products should be careful to provide an appropriate level of scaffolding to facilitate student learning from the model, as well as to recognize that scaffolding should be commensurate with students' prior experience, "models are necessarily denatured from the real by the medium in which they are expressed. Designers must select a level of denaturing matching the target learner's existing knowledge and goals" [19, p. 514]. This is a balance in the development of PCS simulations that we are still attempting to find. Some of our plans include: a) refining activities so they are not as difficult for the target audience; b) including "Easter eggs" for more advanced students to find (and so as to not turn them away from the more basic nature of the standard narrative); c) providing better educational scaffolding (e.g. documentation and in-class, teacherled support); and d) adding character helps that can be triggered by players (e.g. chat responses to common requests for assistance).

\subsection{Integrating a PCS into the Classroom}

Another challenge encountered with the Cybermatics PCS was effectively integrating it into a classroom environment. By their nature, authentic learning experiences encourage a sense of exploration and uncertainty that can be difficult to reconcile with classroom expectations of order and predictability. This is not unrelated to our previous discussion of educational scaffolding, but beyond the learning affordances of scaffolded environments we recognized other expectations of both teachers and students that must be reconciled with the characteristics of the PCS.

Yet the expectations our participants held about effective educational environments were also not consistent, and it was difficult to reconcile these expectations that sometimes conflicted. For example, an expectation of the teacher and the class TA was that the PCS narrative not be so open-ended that it was difficult to manage the classroom environment. Teachers want at least some ability to predict what students would be doing in-class at any given time, so if they need to bring the entire group together for a discussion or presentation that they knew everyone in the class would have a common foundation from which to participate. Some students had a similar expectation for order; we observed that they expected a clear "right answer" to the activities in which they were engaging. For example, a student reported that something to make the simulation better was, "a clear understanding of when a task is finished." While we cannot state for certain what task(s) this student was referring to, we do observe that some tasks in the PCS are intentionally vague - mirroring the vagueness that sometimes accompanies professional practice in the cybersecurity field.

Yet even as we recognize the legitimacy of the classroom expectations expressed by some of our participants, others in the pilot test expressed conflicting desires that in some ways are cross-purpose with an expectation that the PCS be completely clear and predictable. For example, $15 \%$ of students reported being bothered when they encountered something in the PCS that broke the expectation for realism that had been built up throughout the experience. They often expressed this when they tried to explore beyond the bounds of the programmed scenarios. One student described how it was bothersome that the SQL injection only responded to certain inputs that the simulation required students to perform. This student reported wanting to explore further than the scope of the task, but because the PCS was only a simulated environment was unable to do so. The student stated, "the Riptech login page seemed to me like a keyword SQL reference. For example, if you put in anything other than exactly what it's looking for, you receive a 'query failed' notice. Even when trying to $\log$ in with the passwords I obtained, or if my SQL query isn't exactly what it was looking for. In essence, I really couldn't explore beyond the immediate scope of the task." Although having only $15 \%$ of students specifically comment that the PCS should have been more realistic seems small, when we augment this with the $56 \%$ who specifically mentioned that they found value in the realistic environment, we conclude that there is a real tension among students (and in some cases possibly even within the same student) between making the PCS predictable and orderly versus unpredictable and authentic.

Addressing this tension led us to a design principle that attempts to integrate a sense for students using the PCS that the situation is authentic, while still providing predictability for both teachers and students when such is needed. We call this principle "providing the illusion of control," rather than creating a simulation with actual, open-ended control. The clearest example of the illusion 
of control is dividing the PCS simulation into five, distinct "days," that are defined by a scope of tasks to accomplish each day. Within an individual day, students can explore, experiment, complete tasks in an individual order based on their prior experience, study, or even intuition. But once they complete the tasks for that day the simulation concludes until they or their teacher actively choose to advance to the next day. We recognize such an artificial control of moving day-today seems to violate the principle of TINAG. Yet, it is a trade-off our team has been willing to make to provide students and teachers with an understanding of where they are within the simulation, and provide students with clear milestones of accomplishment (e.g., by completing a day they know they have found a "right answer" that they can use to evaluate their own progress). In concept, structuring a PCS by days is not different from the controls available in traditional ARGs, where the parameters of the game do, in fact, limit what players can and cannot do to a significant degree, but the shape of the narrative discourages players from exploring outside paths while encouraging them to explore paths where player control is more available. And while it may not provide the unlimited control that some students expect, it does seem to provide enough control to satisfy many. Implementation of the chat-bot was also a way to provide the players with the illusion of control, as their own messages can trigger custom responses, though our initial prototype was relatively linear in its implementation.

\section{Discussion}

Our findings point toward real tensions in the design and development of immersive educational products and systems, that can have identifiable consequences on the experience students have while learning a subject area. These consequences are as important to study as are the more objective evaluations often conducted on educational products, such as their effect on students' test scores. The less-perceptible, but still real, consequences that we identify as our findings influenced whether some students thought they could be successful as a cybersecurity professional, as well as having an impact on how well they perceived they learned the material. This suggests that improving educational environments demands that we attend to the whole student experience and not only those components that are easy to measure. Likewise, we encourage stakeholders to expand their definitions of success to include broader inquiry into the effects of educational products, such as we have conducted here, and not only hold educators or product developers accountable for the more commonly-used measures of success.
Yet we also recognize that the type of inquiry in which we engaged does not always lead to clear criteria by which others can determine how to apply findings to their own situations. This is the nature of research around matters of design judgment. As Dunne stated, research and theory related to what he called the "practical judgment" of professionals should act as "a kind of reinforcement which helps [them] to be more alert regarding the nature of [their] own task" [26, p. 161]. What professionals should hope for are insights that help them better apply their own reason and experience, rather than prescriptions they should follow.

To assist readers with such a task, we provide a set of questions which can be used to reflect on designers' own circumstances, and consider what applicability, if any, our findings have for their work:

- If you are working in an interdisciplinary team, have you audited the process by which the team works to determine whether all disciplines are adequately contributing the strengths they bring to the collaboration?

- What, if anything, in your design process might be contributing to students having an unclear or ineffective experience?

- Does the order in which team members perform their work matter?

- How are you attempting to balance competing principles in your product development?

- Is pursuit of one principle interfering with the ultimate results you hope to achieve?

- How can you fulfill the demands suggested by all the principles to which you hold as important to your ultimate success, even when such principles may come into conflict with each other?

- Are you observing how your product is actually being used in the classroom environment (if applicable)? If so, are you paying attention to how the affordances of your product align or misalign with the broader system to which teachers and students are enculturated?

\section{Conclusion}

Our purpose has been to describe tensions and difficulties that can arise during PCS development. We have focused on three types of tension in our discussion, all of which arose during the development and pilot test of the Cybermatics PCS: a) the challenges created by working in interdisciplinary teams; b) reconciling the principle of TINAG with the need for educational scaffolding; and c) integrating the PCS into the broader classroom environment. We also provide lessons learned and design recommendations that readers can consider if they are interested in developing a PCS (or 
similar educational experience). But these lessons are only some of the possibilities. While we believe they were appropriate for our circumstances and are worthy of consideration by others interested in adopting the approach, we also hope that ultimately our experiences inspire readers with a sense of what they may be able to accomplish themselves.

\section{Acknowledgements}

Funding for part of this work was provided by NSF grant AISL \#1323787.

\section{References}

[1] R. J. Swartz and D. N. Perkins, Teaching Thinking: Issues and Approaches. London, UK: Routledge, 2016.

[2] G. Bulman and R. W. Fairlie, "Technology and Education: Computers, Software, and the Internet," Handb. Econ. Educ., vol. 5, no. 9432, pp. 239-280, 2016.

[3] M. E. Gredler, "Games and Simulations and Their Relationship to Learning," in Handbook of Research on Educational Communications and Technology, 2nd ed., D. H. Jonassen, Ed. Mahwah, NJ: Lawrence Erlbaum Associates, Inc., 2004, pp. 571-581.

[4] E. Bonsignore, D. L. Hansen, K. Kraus, and M. Ruppel, "Alternate Reality Games as Platforms for Practicing 21st-Century Literacies," Int. J. Learn. Media, vol. 4, no. 1, pp. 25-54, 2013.

[5] H. Jenkins, Convergence Culture: Where Old and New Media Collide. New York, NY: NYU Press, 2006.

[6] J. Kim, E. Lee, T. Thomas, and C. Dombrowski, "Storytelling in New Media: The Case of Alternate Reality Games, 2001-2009," First Monday, vol. 14, no. 6. 2009.

[7] J. Battles, V. Glenn, and L. Shedd, "Rethinking the Library Game: Creating an Alternate Reality with Social Media," J. Web Librariansh., vol. 5, no. 2, pp. 114-131, 2011.

[8] J. Johnston, A. P. Massey, and R. L. MarkerHoffman, "Using an Alternate Reality Game to Increase Physical Activity and Decrease Obesity Risk of College Students," J. Diabetes Sci. Technol., vol. 6, no. 4, pp. 828-838, 2012.

[9] R. Heitzmann, "Case Study Instruction in Teacher Education: Opportunity to Develop Students' Critical Thinking, School Smarts and Decision Making," Education, vol. 128, no. 4, 2008.

[10] D. L. Hansen, J. Balzotti, L. Fine, and D. Ebeling, "Microcore: A Playable Case Study for Improving Adolescents' Argumentative Writing in a Workplace Context," in 50th Hawaii International Conference on System Sciences, 2017.

[11] D. W. Shaffer, "Epistemic games," Innov. J. Online Educ., vol. 1, no. 6, Article 2, 2005.
[12] T. Flushman, M. Gondree, and Z. N. J. Peterson, "This is Not a Game: Early Observations on Using Alternate Reality Games for Teaching Security Concepts to First-Year Undergraduates," in 8th Workshop on Cyber Security Experimentation and Test (CSET 15), 2015.

[13] E. Bonsignore, V. Moulder, C. Neustaedter, D. L. Hansen, K. Kraus, and A. Druin, "Design Tactics for Authentic Interactive Fiction: Insights from Alternate Reality Game Designers," in CHI 2014, 2014.

[14] N. C. Chesler, A. R. Ruis, W. Collier, Z. Swiecki, G. Arastoopour, and D. W. Shaffer, "A novel paradigm for engineering education: Virtual internships with individualized mentoring and assessment of engineering thinking," J. Biomech. Eng., vol. 137, no. 2, pp. 1-8, 2015.

[15] D. W. Shaffer, "Pedagogical Praxis: The Professions as Models for Postindustrial Education," Teach. Coll. Rec., vol. 106, no. 7, pp. 1401-1421, 2004.

[16] G. Dall'Alba, "Learning professional ways of being: Ambiguities of becoming," Educ. Philos. Theory, vol. 41, no. 1, pp. 34-45, 2009.

[17] J. Lave and E. Wenger, Situated Learning: Legitimate Peripheral Participation. New York: Cambridge University Press, 1991.

[18] J. S. Brown and P. Duguid, "Stolen Knowledge," in Situated Learning Perspectives, no. 1, H. McLellan, Ed. Englewood Cliffs, NJ: Educational Technology Publications, 1996, pp. 47-56.

[19] A. S. Gibbons, "Model-Centered Instruction," $J$. Struct. Learn. Intell. Syst., vol. 14, pp. 511-540, 2001.

[20] E. Bonsignore, D. Hansen, K. Kraus, A. Visconti, J. Ahn, and A. Druin, "Playing for real: designing alternate reality games for teenagers in learning contexts," in 12th International Conference on Interaction Design and Children, 2013, pp. 237-246.

[21] J. Giboney et al., "Theory of experiential career exploration technology (TECET): Increasing cybersecurity career interest through playable case studies," in 2019 52nd Hawaii International Conference on System Sciences., 2019, pp. 1-10.

[22] S. B. Merriam and E. J. Tisdell, Qualitative Research: A Guide to Design and Implementation, 4th ed. San Francisco, CA: Jossey-Bass, 2016.

[23] Center for Cyber Safety Education, (ISC)2, Booz Allen Hamilton, Alta Associates, and Frost \& Sullivan, "2017 Global Information Security Workforce Study Benchmarking Workforce Capacity and Response to Cyber Risk," 2017.

[24] D. J. Kay, T. J. Pudas, and B. Young, "Preparing the Pipline: The U.S. Cyber Workforce for the Future," Def. Horizons, vol. 72, pp. 1-16, 2012.

[25] M. O'Keeffe, "Science fiction media fandom and informal science education," J. Sci. Fict., vol. 1, no. 3, pp. 24-39, 2017.

[26] J. Dunne, Back to the rough ground: Practical judgment and the lure of technique. Notre Dame, IN: University of Notre Dame Press, 1997. 